\title{
Fútbol en femenino. Notas para la construcción de una historia social del deporte femenino en España, 1900-1936
}

\author{
Xavier TORREBADELLA-FLIX
}

Universidad Autónoma de Barcelona.

Grupo de Investigación Social y Educativa de Actividad Física y Deportiva del INEFC-Barcelona

xtorreba@gmail.com

Recibido: Febrero 2015

Aceptado: Marzo 2016

\section{RESUMEN}

En el contexto de las demandas del movimiento feminista europeo del primer tercio del siglo $\mathrm{XX}$, en España el deporte femenino puso en escena las aspiraciones de prácticas consideradas del dominio masculino. Las primeras incursiones de las mujeres en el fútbol se destacaron por su utilización mediática como símbolo de una transformación social hacia la modernidad del siglo XX. No en balde, el fútbol femenino puso de relieve las reivindicaciones del movimiento feminista, aunque encontró la desaprobación masculina de un movimiento adversario. La investigación ha partido de la revisión bibliográfica y hemerográfica de la prensa especializada y de las noticias deportivas de la época. Asimismo se han tenido en cuenta otros estudios actuales para centrar una posición desde la historia social del deporte. Ello ha permitido destacar que el fútbol en España se estableció como un inequívoco espacio (re)productor del modelo hegemónico del poder de la masculinidad, en donde las mujeres fueron relegadas a representar un ritual simbólico en un escenario accesorio y de condescendencia.

Palabras claves: Fútbol femenino, historia del deporte, feminismo, discriminación sexual.

\section{Women's football. Notes for a social history of women's sport in Spain,} 1900-1936

\begin{abstract}
In the context of demands by the European feminist movement at the beginning of the 20th century, in Spain women's sport flagged up aspirations to what were considered to be male practices. The first experiences of women in football stand out because of their use of the media to appear as a symbol of social transformation to modernity in the 20th century. It was not in vain that women's football highlighted the demands of the feminist movements, although it did


come up against male disapproval from an opposing group. The research sets out from a bibliographical and media review of specialist press and sports news of the time. Other current studies have also been considered in order to place it in a social and historical focus on sport. This has enabled us to highlight that football in Spain was established as an unequivocal space for (re) producing male hegemony where women were relegated to the representation of a symbolic ritual in a scenario of accessory and condescension.

Key words: Women's football, history of sport, feminism, sexual discrimination.

\section{INTRODUCCIÓN}

El fútbol en España ya es uno de los principales deportes colectivos practicados por la mujer. Van quedado ya doblegadas todas aquellas opiniones recalcitrantes que trataron de alejar a la mujer del llamado “deporte rey”. El fútbol femenino se encuentra extendido a todos los niveles, escolar, recreativo y competitivo, y a pesar del dominio en la reproducción de los estereotipos tradicionales (Llopis, 2011; Soler, 2009), en nuestra opinión ira todavía en aumento (UEFA, 2015). Sin embargo, el llegar hasta aquí ha supuesto un recorrido histórico de más de un siglo en el desarrollo del deporte contemporáneo. Hoy podemos conmemorar los cien años de la presencia del fútbol femenino en España. Tras el largo paréntesis del período de la dictadura franquista, la progresión de este deporte ha alcanzado las aspiraciones de aquellas jóvenes que por primera vez se lanzaron a romper con los prejuicios de una sociedad, hasta no hace mucho, excesivamente conservadora en sus relaciones de género.

Como trata Hargreaves (1993), la construcción social del deporte se ha fundamentado en la historia hegemónica de la autoridad masculina. En este escenario y en la inmensidad de contextos y situaciones se ha menospreciado el protagonismo de la mujer e incluso se la ha hecho invisible. Desde la aparición del deporte como proceso de civilización y de ocio, las mujeres siempre trataron de legitimar su propio espacio y, en el marco de las reivindicaciones feministas, "cada vez más mujeres lucharon simultáneamente para combatir la idea de que el deporte era meramente legítimo como una reserva masculina" (Dunning, 2003: 271). Sin embargo, la impronta de un modelo de masculinidad en el anquilosado deporte español constituyó especialmente en el fútbol un espacio hegemónico y de exclusión femenina (Uría, 2008).

El objeto de estudio se centra en presentar las primeras noticias del fútbol femenino en España en el contexto histórico social de las relaciones de género. Esta aportación, todavía inédita, debe contribuir a la construcción de una historia social del deporte femenino en el siglo XX.

\section{MATERIALES Y MÉTODO}

Los estudios que se ocupan del deporte femenino en España son escasos (Carbajosa y Riaño, 2009; Fernández, 1988; García, 1989, 1992, 2001; García-García, 2015). Izquierdo y Gómez, 1999; Justribó, 2014; López-Villar, 2014; Pastor, 2011; Pujadas, 2013; Real, 1998, 2010; Riaño, 2004a, 2004b; Simón, 2009; Sánchez y Rivero, 2013) y como considera Simón (2009), aún representan una posición 
secundaria y marginal. Si bien estas aportaciones colaboran a contextualizar un aspecto genérico del deporte femenino, son también la base para sustentar otros estudios más específicos y particulares. En nuestro caso, pretendemos contribuir a engrosar la temática, pero es precisamente, a partir de la aproximación singular del fútbol.

La investigación parte de la revisión documental en las principales bases de datos digitalizadas y abiertas en Internet. Esencialmente, la documentación tratada ha tenido como fuentes la Hemeroteca Digital de la Biblioteca Nacional, las revistas antiguas de la prensa catalana en ARCA y las hemerotecas de La Vanguardia y El Mundo Deportivo. El vaciado documental y la clasificación cronológica de las noticias o informaciones hemerográficas ha contribuido al análisis hermenéutico de las fuentes, que también se ha sustentado con los estudios anteriormente citados y con otros específicos de género.

\section{EL DEPORTE FEMENINO EN ESPAÑA DESDE FINALES DEL SIGLO XIX}

Las noticias acerca de los movimientos feministas internacionales y el deporte también eran presentadas en España. En La Vanguardia de Barcelona se ofrecía la noticia de los partidos de foot-ball disputados en Londres entre las colegialas de Ground y de Hornsey (Franco, 1895a, 1895b). La noticia también se publicó en El Pelotari, que celebró el suceso sin mostrar opinión alguna (Señoras pelotaris, 1895). Sin embargo, el citado acontecimiento marcó en Inglaterra un punto de inflexión en cuanto a las primeras reivindicaciones de signo feminista del deporte contemporáneo. La iniciativa partió de una esmerada organización que distribuyó carteles por toda la ciudad. Ante un numeroso público, cuentan que unas diez mil personas, se disputó el enfrentamiento entre los equipos llamados Norte, vestido de rojo, y Sur, vestido de azul oscuro. Las críticas periodísticas de la época pusieron de relieve que las jóvenes no entendían nada de fútbol, circunstancia que ante la ridícula situación provocó que la mayoría del público abandonase el estadio (Femenine football. A revolting exhibition, 1895; Tate, 2013).

En España, este tipo de manifestaciones perdían protagonismo con opiniones como las de Emilia Pardo Bazán (1896), que prefería una pasividad de la mujer ante los espectáculos viriles como el polo o el foot-ball, que recordaban los antiguos torneos en donde las damas ofrecían el beneplácito aplauso:

"Tiene además el polo algo que recuerda los antiguos torneos: la presencia de la mujer, su aprobación, su aplauso. La caza es de suyo insociable; la equitación lo mismo; otro tanto podría decirse del foot ball, que aquí, por otra parte, no ha cuajado ni lleva trazas de cuajar nunca. El tennis es cosa más bien infantil, aunque lo jueguen algunas señoras por lucir el talle; en las carreras, los que toman parte activa en el espectáculo son los jockeys, gente mercenaria. En el polo, los jugadores son caballeros, y las que presencia, señoras de su misma sociedad, sus hermanas, sus madres, sus novias, sus amigas; y a la cabeza de las damas mironas figura nuestra más decidida sportwonan, la Infanta Isabel” (Pardo, 1896: 466). 
En 1896 las mujeres no tomaron parte en los Juegos Olímpicos (JJ.OO). La primera participación fue en 1900 en París, pero solamente en las prácticas de tenis, croquet y golf. Paradójicamente esta escasa presencia coincidía con la imagen de la esgrimista de uno de los populares carteles publicitarios de la Olimpiada de París; que quizás pudiera representar una peculiar metáfora que indicaba la lucha del feminismo por sus derechos. Es conocido el carácter misógino del barón Pierre de Coubertin, que fue el principal adversario de la participación de las mujeres en los JJ.OO (Mason, 1994; Rodríguez, Martínez y Mateos, 2005). Los reparos y los prejuicios fueron de toda índole. En esta época había quien llamaba "marimacho a la mujer que se pone pantalones para ejercitar el ciclismo" (Pastor, 1997: 10).

En España ya se había puesto en marcha la labor propagandística a favor de la educación física de la mujer en manos de la Institución Libre de Enseñanza. El momento coincidió con la genuina llegada del sport femenino a través del ciclismo, que daba entrada a situar a la mujer en las tesis regeneracionistas del período. Sin embargo, la práctica deportiva femenina se ceñía al reservado espacio de los ambientes burgueses, en donde especialmente las señoritas y algunas mujeres atrevidas podían librarse, no sin razón, mostrando un oculto manifiesto feminista (Torrebadella, 2011a).

Como apunta García-Ferrando (1989), el modelo deportivo anglosajón estaba marcado por el ideal caballeresco y sexista victoriano. En esta coyuntura no fue bien vista que la delicada mujer complaciente, reservada, sumisa y entregada a los quehaceres maternales y domésticos, desatendiera sus obligaciones para dedicarse a las prácticas deportivas, consideradas fuera de los dominios de su propia naturaleza. En España, durante el periodo de la Restauración, este arquetipo fue mimetizado y modeló la identidad de la mujer burguesa y de clase media. La Reina Victoria Eugenia de Battenberg se proyectó a través de los reportajes de las revistas ilustradas como la icónica representación de un modelo aristocrático femenino del deporte. Una mujer, que junto a su marido Alfonso XIII, lucía un elevado estilo de vida, de aires británicos, a través de la práctica de deportes como la equitación, la vela, el tenis, el patinaje, la vilorta, el tiro o el golf (González, 2011). No obstante, como considera Bahamonde (2011: 17), en España el sistema deportivo fue "organizado por hombres y para los hombres” y, en esta situación, la inmensa mayoría de las mujeres quedaron relegadas al ostracismo de los dominios viriles del deporte (Sánchez y Rivero, 2013).

Vicente de Castro (1906: 2-3), director de la revista deportiva Gran Vida, reconocía al hockey "muy a propósito para señoritas”, pero añadía "que el sport como competencia física está absolutamente fuera de la esfera de la mujer, pero al mismo tiempo pensemos que el saludable ejercicio al aire libre es una necesidad para todo organismo viviente".

El deporte femenino en España fue prácticamente inexistente hasta llegar a la década de los años veinte. Hasta entonces, las prácticas de signo elitista y diferencial solamente residían en una minoría de señoritas de la alta sociedad (Bahamonde, 2011; Simón, 2009). Los deportes en los que la mujer participaba tenían un carácter individual, y en la mayoría de las situaciones, con la inseparable compañía masculina: la caza, la equitación, el tenis, el ciclismo, el excursionismo, el esquí, el tiro al pichón, el patinaje o el baile. De vez en cuando las mujeres participaron en alguna que otra 
eventual y frívola competición, que todavía no podía identificarse con ninguna institucionalización del deporte femenino.

El cambio de rumbo vino fraguado por el hockey hierba. Hacia 1918, la creación en el Club Athletic de Madrid de un equipo femenino de hockey promovido por jóvenes estudiantes, llevó en poco tiempo a lograr el primer campeonato del deporte femenino español (Deportes femeninos, 1918) ${ }^{1}$. En 1920 se constituyó oficialmente la Sección femenina del Club Athletic de Madrid (Sánchez, 2005).

Las jóvenes del Club Athletic citaban que practicaban el hockey no para lucir el talle, sino por exclusivo amor al deporte y por diversión. En los años veinte, la necesidad de acercar el deporte a la mujer se enmarcó en el discurso regeneracionista (Torrebadella, 2014; Torrebadella y Ticó, 2014). En la prensa se reflejaron posiciones que trataron de apadrinar el deporte femenino pensando en la madre futura que "necesita ser física y espiritualmente fuerte para la fortaleza de la raza y la sanidad de los ciudadanos de mañana que regeneren esta España nuestra tan pobre y mezquina" (Vidal, 1923: 4). Así, las madrileñas se habían lanzado con el hockey a la verdadera conquista del deporte femenino, como ya lo hacían las mujeres de Inglaterra, Francia o Alemania. A partir de la iniciativa madrileña, en las páginas de Gran Vida se estaba pidiendo a ciudades como Barcelona, Bilbao, San Sebastián, Sevilla o Vigo la organización de equipos con el fin de establecer "un campeonato a semejanza del sexo fuerte" (Hockey y Feminismo, 1923: 13).

El ambiente progresista y libertino de los llamados "felices años veinte", junto a la expansión popular del deporte, generada especialmente por el boom futbolístico, facilitó una coyuntura social en donde la mujer encontró aspiraciones superiores. Esta situación fue reforzada por la prensa deportiva, que en una actitud regeneracionista concedió apoyo a la expansión de las prácticas deportivas entre las mujeres (Torrebadella, 2011b). Sirvan de ejemplos revistas como La Jornada Deportiva, Aire Libre, L'Esport Català o Stadium. Sin embargo, en esta época aparecieron los primeros elementos recalcitrantes del deporte femenino. Periodistas como Román Sánchez Arias (Rubrik, 1921) o influyentes directivos del deporte como Emilio César Porras (1925) o el doctor Manuel Bastos (1927) pusieron límites al deporte y reparos a las prácticas deportivas de las mujeres.

Tras finalizar la I Guerra Mundial las reivindicaciones sufragistas se intensificaron en toda Europa y el deporte fue uno de los mecanismos más poderosos para intervenir (Bahamonde, 2011). No debe sorprender que en aquella época se presentasen en Madrid dos equipos femeninos de la Federación de Sociedades Deportivas Femeninas de Francia, que a través de los contactos con la Real Sociedad Gimnástica Española hicieron posible varias exhibiciones con el propósito de estimular el deporte entre las jóvenes españolas, como ya se estaba realizando en el extranjero (Real Sociedad Gimnástica Española, 1921: 12). Sobre la intención de fomentar el

\footnotetext{
${ }^{1}$ En Barcelona el 1 de octubre de 1912 se constituyó el Femenina Natación Club que presidió Clementina Ribalta, que tiene el honor de ser la primera asociación femenina del deporte en España (Navarro, 1917, p. 114-115).
} 
deporte de signo feminista se añadía que "mucho tememos que la loable iniciativa de la Gimnástica no surta el apetecido efecto. Vivimos en un país en el que todavía se discute el traje de baño que las mujeres han de bañarse en la playa" (Feminismo deportivo, 1921: 369).

En la década de los años veinte hubo un debate sobre si la mujer debía, o no, participar en los JJ.OO. En Europa y América del Norte, la mujer había consolidado un status deportivo considerable, participando en distintas modalidades y en campeonatos internacionales. La esgrima, la natación y el tenis femenino ya estaban presentes en los JJ.OO de París (1924) $)^{2}$. La prensa deportiva y las revistas de sociedad dedicaban espacios para el deporte femenino. Se trataba de ilustrar un concepto de progreso y modernismo a través de la fotogenia deportiva de la mujer. Así sucedía en las numerosas portadas de la revista semanal Aire Libre (1923-1925), impresa por la Prensa Gráfica. Tanta publicidad, sin duda alguna, ponía el acento en incentivar la práctica del deporte femenino. Esta propaganda tomó un mayor protagonismo a partir de las Olimpiadas de 1924, cuando se alcanzó en la especialidad de tenis la primera participación femenina del deporte español, en las figuras de Rosa Torres y Lilí Álvarez. Fue precisamente la mítica imagen de Lilí Álvarez la que encarnó la mejor representación nacional e internacional del deporte femenino (De la Arada, Turró y Vilanou, 2013; Carbajosa y Riaño, 2010; Riaño, 2004a).

La emergencia del deporte femenino internacional en España fue fuertemente frenada desde los sectores más conservadores. La llamada tendencia del "feminismo deportivo", fue visionada como una amenaza a la hegemonía política masculina. En el Heraldo Deportivo algunos eventuales artículos pusieron objeciones que ridiculizaban el ascenso del deporte femenino internacional: "Por nuestras tierras seguimos sin atisbos de que el feminismo se adentre en deportes atléticos. Fuera de las apariciones meteorológicas del hockey las muchachas españolas no se encuentran dispuestas para más deporte que el tennis” (Feminismo deportivo, 1922: 263). Sin embargo, se pronunciaban voces que trataron de incentivar el desarrollo deportivo femenino. Ante la lamentable participación de la mujer española en el deporte, que se reducía solamente a la práctica aristocrática del tenis por algunas señoritas, había quien proponía imitar el ejemplo de otros países (Del Olmet, 1922).

Ante los progresos del deporte femenino en el extranjero y al comprobar que las mujeres utilizaban pantalones deportivos de hombres y practicaban deportes de armas se pedía "que las cosas queden por nuestras tierras, en el estado que están" (Femeninas, 1923: 511). De igual modo, se criticaba el ciclismo de competición femenino que en Francia se practicaba con bicicletas e indumentaria hombre (Ciclismo femenino, 1925). Las críticas al atletismo femenino sostenían que la mujer no debía romper el equilibro de belleza y las defensas musculares y orgánicas para cumplir su "misión divina en la tierra” (Atletismo femenino, 1926: 448).

${ }^{2}$ La primera participación femenina fue en los JJ.OO de París en 1900, en el que el tenis y el golf fueron considerados deportes idóneos para las señoritas. 
En los años veinte, posiciones como las de Gregorio Marañón (1934), que tenía al deporte como una actividad originariamente masculina en donde la mujer vivía de prestado en el ambiente deportivo, mientras no la llamasen los hábitos de la maternidad, representaban un amplio consenso de la población (Burgos, 2001). Es por esta razón, que del mismo modo que Emilia Pardo, Marañón añadía que la trascendencia de la mujer en el deporte tenía su sentido sexual: "está allí para servir de acicate y de premio al jugador de ahora, como al caballero de las justas medievales" (Marañón, 1934: 68-69).

La prensa deportiva catalana -Stadium, La Jornada Deportiva o L'Esport Catalàno ponía reparos al deporte femenino, los estimulaba y seguía como modelo la emergencia del movimiento deportivo internacional de los años veinte. La Jornada Deportiva, que dedicaba la portada a la Olimpiada Femenina de París, creía que España debía reaccionar ante los ejemplos de salud corporal que la mujer estaba demostrando en el extranjero, y que el mejoramiento de la raza significa "disciplinar el cuerpo de las mismas”. Se añadía, al respecto, que todavía persistían muchos prejuicios y, sobre la capacidad física de la mujer, se trasladaba el ejemplo de muchas de las mujeres de Oceanía y África, poseedoras de un cuerpo más fuerte y robusto que el de "muchos hombres civilizados” (La educación física de la mujer, 1922: 2).

En 1926 L'Esport Català realizaba un llamamiento al deporte femenino, intentando ampliar los horizontes más allá de las pocas mujeres que practicaban el tenis o el excursionismo. El rotativo animaba a practicar atletismo, ciclismo, remo, básquet y otros estimulantes deportes individuales y de conjunto. L'Esport Català brindaba apoyo al deporte femenino y pedía a los círculos femeninos, que ellos mismos fuesen los responsables de organizar su propio desarrollo (Trabal, 1926).

La II República concedió un mejor escenario a la liberación social de la mujer, aspecto que quedó reflejado en una mayor participación en el deporte con la creación de algunas entidades deportivas de signo feminista (Torrebadella, 2011b), que siguieron el modelo del Club Femení i d’Esports de Barcelona (Real, 1998) o de las Legionarias de la Salud de Madrid (Campo, 1931).

El Dr. Mollá (1931: 47) veía en el deporte un elemento poderoso para asaltar la independencia social de la mujer; una situación que debía conducir al equilibrio entre los sexos, y añadía: "El hombre va cediendo en sus intransigencias y va aceptando como compañeros y hasta como jefes a aquellas mujeres que tiempo atrás sólo admitiría como esclavas, mujeres, o como criadas”. Sin embargo, la prescripción facultativa del deporte debía considerarse atendiendo la diferenciación de sexos, puesto que a la mujer no se le podía permitir las mismas exigencias físicas que al hombre. Deportes como el boxeo, fútbol o rugby aún continuaban reservados a las características fisiológicas del hombre, mientras que la mujer debía frecuentar deportes más acordes con su sexo "dulcemente dosificados”, como la natación, el baloncesto o el tenis.

La centralidad que ha supuesto el protagonismo de Lilí Álvarez, la más internacional deportista del primer tercio del siglo XX, no fue representativa de las aspiraciones de la mayoría de las mujeres. Álvarez encarnaba el aristocrático prototipo de mujer deportista idealizado por el hombre, un modelo que mantenía el equilibrio 
entre las aspiraciones de la mujer y los deseos de feminidad de las posiciones más conservadoras (Pastor, 2011). Secularmente, las mujeres de la pequeña burguesía y de las clases medias vinculadas a los movimientos sufragistas y de izquierdas aspiraban que el deporte fuera el estímulo de la emancipación femenina, visionando la idea de la "nueva mujer", así como reivindicaron las primeras entidades populares del deporte femenino (Fernández, 1988; Justribó, 2014; Real, 1998).

Como trata Barbero (1993), la actividad física también en la mujer fue temida como peligrosa puesto que podía liberar la conciencia corporal, hasta entonces puesta al dominio de las relaciones de saber/poder que trataron de mantener el vínculo de la condescendencia liberal a los designios de maternidad que profesaba la influyente iglesia católica.

Las contradicciones de una sociedad liberal y progresista no podían salvaguardar durante mucho tiempo el altar inmaculado de la mujer. Los esfuerzos por mantener el status quo de privilegio de las clases acomodadas fueron contrariados por la emergencia social de las clases comerciales y obreras, que aprovecharon el descanso dominical para estímulo y recreación deportiva. Es precisamente en las clases medias en donde la mujer se enfrentó a los prejuicios sociales dominantes de la masculinidad y requirió las prácticas deportivas como uno de los mecanismo para trasladar sus pretensiones.

En el caso particular de España, fueron principalmente los deportes colectivos como el hockey, el baloncesto o el balonmano en donde se institucionalizó el deporte femenino de clase media, una identidad que tuvo su momento más álgido en el período de la II República (Justribó, 2014; López-Villar, 2014; Torrebadella, 2013; Torrebadella y Ticó, 2014). Una excepción fue el fútbol, conceptuado como el templo sagrado de la masculinidad y en donde la participación de la mujer quedó reservada a un papel secundario de espectadora y admiradora. Como trata Bourdieu (2000), son precisamente los deportes más viriles como en el fútbol en donde se construyen y se institucionalizan los dispositivos que predisponen las diferencias de la heterosexualidad:

"En la medida en que la socialización diferencial dispone a los hombres a amar los juegos de poder y a las mujeres a amar a los hombres que los juegan, el carisma masculino es, por una parte, la fascinación del poder, la seducción que ejerce la posesión del poder, por sí misma, sobre unos cuerpos cuyas pulsiones e incluso deseos están siempre socializados.” (Bourdieu, 2000: 101-102).

Así pues, si en este contexto algún deporte levantó ampollas fue el caso del fútbol, el llamado deporte viril, reservado a los hombres fuertes y no, al todavía, llamado "bello sexo".

\section{LOS PRIMEROS INTENTOS FUTBOLÍSTICOS FEMENINOS}

En 1914 llegaban a España noticias del festival deportivo organizado por el gremio de artistas de los Music-halls de Londres en beneficio de su Montepío. De este 
evento o festival "burlesco" y recreativo se destacaba el partido de foot-ball disputado por algunas artistas ante un numeroso público que se concentró en el estadio de Tottenham (Festival de artistas de varietés, 1914). Precisamente en este mismo año, en Barcelona se estaban organizando los primeros equipos femeninos de la historia del fútbol español. La noticia saltó cuando en junio de 1914 se presentó la asociación cuyo nombre adoptó Spanish Girls Club. El 9 de junio esta asociación confraternizó los equipos Montserrat y Giralda, los cuales disputaron un primer partido en el campo del RCD Español en beneficio de la tuberculosis. Las voces de la prensa deportiva fueron refractarias. El Mundo Deportivo decía: "Esta primera actuación de la mujer en el viril fútbol no nos satisfizo, no solo por su poco aspecto sportivo sino porque a las descendientes de la madre Eva les obliga a adoptar tan poco adecuadas como inestéticas posiciones que eliminan la gracia femenil” (Las niñas futbolistas, 1914a: 4). En un segundo partido celebrado ante un escaso público, El Mundo Deportivo citaba que "por segunda vez las niñas futbolísticas no convencieron a las personas amantes de lo bello, en todos sus aspectos" (Las niñas futbolistas, 1914b: 5). De todos modos, ambos equipos realizaron una gira por otras poblaciones catalanas -Sabadell, Badalona, Mataró, Manresa y Reus-, pero las criticas de actividad ridícula y la poca afición que despertó en su género, inhibió el desarrollo de la iniciativa (Arrechea y Scheinherr, 2015; García-García, 2015; G-Luque, 2011; Justribó, 2014). Según GarcíaCastell (1968), estos equipos entrenados inicialmente por Jack Greenwell y luego por Paco Brú, fueron contratados para disputar un gira por Francia, pero el infortunio de I Guerra Mundial paralizó definitivamente la iniciativa.

En Inglaterra durante la campaña de la Gran Guerra, el fútbol femenino retomó un espontáneo protagonismo entre los equipos formados por las empleadas de las fábricas de munición. Esta nueva reacción representó el germen de la iniciación del fútbol femenino en Europa (Brennam, 2007; Simón, 2009; Tate, 2013). Las noticias del fútbol femenino inglés llegaban a España. En Barcelona, aunque reconocían que se trataba de un deporte algo violento para las mujeres, indicaban que con esta moda pronto se podrían llegar a presenciar partidos de chicas futbolistas en la ciudad (A l'hora del te, 1919). Pero esta posibilidad era un tanto remota cuando había quienes, de entrada, negaban la oportunidad a que las jóvenes se iniciaran en este deporte. El sportsmen José Elias Juncosa (1918: 130), uno de los principales promotores del deporte en Cataluña y seguidor de Pierre de Coubertin, consideraba que el fútbol era un deporte viril que desaconsejaba a las mujeres, puesto que ya disponían del basket-ball o push-ball y otros juegos más acordes con su naturaleza.

Al finalizar la contienda militar el fútbol fue presentado como la iconografía anglosajona del deporte de combate, cuyo testimonio había forjado la fortaleza, resistencia y disciplina necesarias para decidir victoria. Las mujeres obreras desde las fábricas también podían contribuir, con espíritu deportivo, al desarrollo de la guerra y, por lo tanto, no se les podía negar "la batalla fingida" del fútbol. Cuando las mujeres dejaron de desear un "cuerpo de princesas" para tener un "cuerpo de guerreras", la intención de dar patadas al balón se hizo mucho más peligrosa que la de manipular bombas con las manos. En Inglaterra la reacción contra el fútbol femenino terminó con su total prohibición en 1921 (Tate, 2013). Además, las aspiraciones del deporte femenino internacional quedaron truncadas ante el rechazo de su participación en los 
JJ.OO de Amberes. Como trata Cagigal (1981: 157), esta situación provocó una reacción adversa y alternativa, por lo que el emergente asociacionismo deportivo femenino europeo decidió organizar sus propios Juegos Olímpicos. En 1921 la iniciativa de Alicie Milliat, pionera del asociacionismo deportivo en Francia, movilizó la creación de la Federación Internacional Deportiva Femenina, que muy pronto organizó unos Juegos Atléticos en Montecarlo con la presencia de Suiza, Inglaterra, Italia, Francia Checoslovaquia, Bélgica (Atletismo, 1922). El nuevo organismo organizó, durante doce años, las "Olimpiadas femeninas" o "Juegos Mundiales de Mujeres” -París (1922), Göteborg (1926), Praga (1930) y Londres (1934)-, que marcaron una reivindicación ante la discriminación que las mujeres recibían del Comité Olímpico Internacional (Arnaud y Terret, 1996). En España, a excepción de $L a$ Jornada Deportiva -25 de agosto de 1922-, que dedicó la portada a la Olimpíada Femenina de París, la prensa deportiva no se ocupó demasiado de las noticias de estos eventos. Al respecto se citaba que "para nuestra desgracia y de la nación, pocas, muy pocas son las representantes del sexo bello, que practican el deporte" (Mestoar, 1922: 3). La ausencia del deporte femenino de matiz reivindicativo en la escena internacional fue completa. Mientras que en Europa la mujer de clase media abanderaba el movimiento deportivo internacional, en la España de los años veinte la imagen de la mujer deportiva tenía como modelo el arquetipo aristocrático cuya ostentativa representación lucia la Reina Victoria Eugenia. Este modelo monárquico se encargaba, por lo tanto, de mantener la firmeza del abolengo de dispositivos decimonónicos que servían al proceso feminización:

"Mucho se ha discutido sobre el tema, y se discutirá, sobre cuál deporte es el que más beneficios reporta al organismo femenino, ya que a éste, por su constitución, no debe estarle permitido realizar ciertos ejercicios físicos, que pugnan, además; con la gracia de la mujer, pues nadie comprendería una muchacha boxeando, luchando o volteando a caballo, deportes en abierta oposición con la finalidad que el deporte tiene por objeto; salud, fuerza y belleza. [...] El vestido deportivo femenino debe ser lo más sencillo posible. La falda plisada, estilo escocés, es la más perfecta y debe llegar hasta más abajo de la rodilla. Las medias deber; llegar hasta donde empieza la rodilla, para no dificultar el libre juego de la misma.” (Los deportes apropiados para la mujer, 1922: 309).

En España las noticias internacionales del fútbol femenino fueron recogidas por la prensa deportiva, aspecto que conllevó abundantes discusiones (Brule, 1920). Comentaba Mariano de Cavia (1920: 201-203) que solamente consideraba el llamado balompié como una práctica del hombre, "que cuando la mujer quiere emular al hombre, no es sino un mono"; por lo que pedía a las chicas que no tuvieran "la cursi tentación de jugar al balompié”. Esta posición fue muy aceptada por un amplio sector de la opinión masculina. Como trata Uría (2008), en los años veinte el fútbol amplificó una representación de la masculinidad cuyo ascenso ha llegado hasta nuestros días como mecanismo inductor de masculinidad (Del Campo, 2003; Llopis, 2010, 2011; Martín y García, 2011).

Por otro lado, en las páginas de el Heraldo de Madrid había quien se posicionaba a favor del fútbol femenino, tal y como ya estaban haciendo otros países como 
Inglaterra, Francia, Alemania o Estados Unidos. Anunciaba que en Irún se constituían dos equipos, que estaban entrenando desde hacía tiempo para disputar un encuentro futbolístico, es más se remarcaba que "las jugadoras lucirán unos lujosos y exiguos maillots que hasta ahora venían utilizando para el baño" (El foot-ball femenino en España, 1920: 5).

Ante la noticia que la Federación Inglesa de Fútbol había prohibido la práctica del juego a las mujeres, Alberto Maluquer (1923: 2) coincidía en determinar que este deporte "es demasiado brutal y fatigoso para la mujer, cuya constitución no es suficientemente robusta”. Sin embargo, a raíz de la constitución en Barcelona de un equipo femenino, en uno de los clubes más importantes de la ciudad, Maluquer no ponía reparos a la práctica de este deporte, aunque prefería que las mujeres se dedicasen mejor a otros deportes como el baloncesto.

En 1923, la prensa deportiva catalana suscitaba el polémico debate sobre el fútbol femenino. El fútbol en la mujer era visto como algo "ridículo", "absurdo" e "intolerable" (Isop, 1923). En la prensa pocas voces se pronunciaron a favor de su práctica y hubo quien se pronunció como completo enemigo de un deporte, calificado del todo indeseable para la mujer (Maria, 1923). De cualquier modo, este mismo año se celebró en Barcelona el primer partido internacional de fútbol femenino entre un equipo francés y otro británico. Este partido se organizó con motivo de la Fiesta deportiva de los periodistas. El periodista deportivo Enrique Guardiola mencionaba al respecto:

"Haga cuanto pueda hacer una girl o uma mademoiselle, y aun más si se atreve...

Pero por ¡Dios! Que no se meta a futbolear, que no pretenda eclipsar a los Alcántara y a los Cros, que lo único que lograra con ello será autoeclipsar sus tradicionales encantos.

Esperemos que los partidos jugados recientemente, y de los cuales damos algunas noticias graficas harto elocuente, servirán de antídoto a los deseos de nuestras deportistas, si es por acaso que hubieran sentido la tentación de futbolear, de la cual nos libre el Señor. Amén.” (Guardiola, 1923: 595).

Ante el partido en beneficio del Sindicato de Periodistas Deportivos se mencionaba que "está ya sobradamente discutido que el fútbol no entra ni mucho menos, en la lista de los deportes que puede practicar la mujer" (El deporte ridiculizado, 1923: 7). La polémica alcanzó un alto recorrido y trascendió a la prensa local. En Lleida, El País publicó, a primera página, un artículo sobre el debate suscitado:

"Es verdaderamente el fútbol, el deporte hoy tan en boga, el menos femenino de todos los deportes. [...] dejen a los hombres el fútbol, pues jamás será bello ver como caen las gráciles damitas a los embates brutales de la lucha, como sufren, sobre las armónicas turgencias de los senos, los golpes rudos del balón y como sus pies, cuya belleza es enemiga del tamaño, calzan los gruesos zapatos del futbolista.

Es el deporte escuela de lealtad y de franqueza, fuente de salud y belleza plástica, 
y sería incalificable egoísmo masculino alejar a las mujeres del deporte para dejarlas solo el paseo, el cine y el baile; a ellas es quizás más útil y más necesario que a los hombres, pero que cultiven deportes apropiados, deportes en los que puedan ser siempre bellas "sporwoman" y que en el campo de fútbol se contenten con el papel de entusiastas espectadoras.” (Martorell, 1923: 1)

En la prensa aparecieron algunas noticias de sociedad que se ocuparon del netball, un nuevo deporte surgido en Inglaterra, que practicado por el sexo femenino tenía la misión de substituir el agresivo juego del fútbol. A pesar de estas noticias y de probablemente algunos intentos esporádicos de este juego "femenino", que ya hacía veinte años que se había divulgado en España (Pastor, 1997: 308), apenas llegó a conocerse:

“Nuevo deporte en Inglaterra.-El «net-ball» En Inglaterra, el país deportivo por excelencia, donde tuvieron su cuna casi todos los sports conocidos, ha comenzado á cultivarse un nuevo juego que no tardará en hacer su aparición en los demás países. El nuevo deporte, dedicado más especialmente á las señoras, se llama el net-ball, y es una variación del popularísimo foot-ball, que tanto apasiona los ánimos en nuestro tiempo. Pero como no estaría bien que damas y damitas deformaran y estropearan sus lindas piernas en el violento ejercicio del «balompié», que dijo Cavia, en el net-ball los balones se impulsan con las manos. Como en el foot-ball, juégase el nuevo deporte por dos bandos, y el objetivo está en meter el balón en el campo contrario, burlando á los guardadores de la portería. En los colegios de señoritas de Inglaterra parece que se juega ya mucho el netball. Las reglas no tardarán en traspasar el Canal de la Mancha y las fronteras, para que el nuevo deporte se imponga en los demás países. Sin embargo, como variedad del foot-ball, el nuevo juego ofrecerá mucho menor interés, y como juego de pelota será inferior al tennis y aún al de nuestra pelota vasca.” (Noticias de sociedad, 1923: 2).

En estos momentos en España surgía un movimiento reaccionario al fútbol y a la especialización deportiva precoz (Torrebadella, 2012). Asimismo desde sectores anarcosindicalistas el fútbol se presentaba como un símbolo bélico entre los pueblos (J. E., 1928).

Ante la noticia de un partido de fútbol internacional disputado en Londres entre dos equipos femeninos -el femenina Sport Club de París y el Dick Kerr de PrestonLancashire- desde las páginas de Gran Vida se pronunciaba que éste era "un deporte poco adecuado para el bello sexo" (Deportes y el feminismo, 1925: 260). También corría la noticia que dos equipos femeninos de Bruselas estaban de gira por España, participando en ciudades como Zaragoza o Vigo. En Zaragoza el partido entre las señoritas belgas se disputó el 20 de octubre de 1925 (Fútbol femenino, 1925). Al respecto se trataba irónicamente el deseo de constituir una Federación Internacional de Fútbol Femenino (De Laiglesia, 1926).

En 1928 en los JJ.OO de Ámsterdam las mujeres tuvieron su primera participación en las pruebas de atletismo y gimnasia. Ésta fue una medida que no gustó a muchos, sobre todo, al barón de Coubertin que siempre había sido reacio a la 
incorporación de la mujer a los Juegos Olímpicos, ya que deseaba ser fiel a la tradición de la cultura helénica de no dejar entrar a las mujeres en el Estadio.

Sin embargo, los prejuicios masculinos de la época no atemorizaron al colectivo feminista, que vio en los deportes y, especialmente, en el fútbol un poderoso medio para cumplir su abnegada lucha en pro de sus derechos e igualdad de oportunidades.

El Montepío de Actores Españoles organizó partidos de fútbol entre las primeras vedettes de los teatros de Madrid (Por el montepío de actores, 1930). Este frívolo evento suscitó nuevamente la posibilidad de promocionar el varonil deporte en el sexo femenino. El asunto provocó que en Madrid se consintiese un campeonato de fútbol femenino entre los recién constituidos Romea FC y Metropolitano FC (Méndez, 1930).

Este protagonismo surgió en el preciso momento en que el deporte femenino popular se lanzaba a la palestra (Pujadas, 2011). Durante el transcurso de la II República el asociacionismo femenino protagonizó una rápida emergencia en el deporte popular y universitario, sobre todo perceptible en la práctica de especialidades como la natación, el atletismo o deportes colectivos como el hockey, el balonmano o el baloncesto (Carbajosa y Riaño, 2009; Justribó, 2014; López-Villar, 2014; Riaño, 2004b). Estos deportes también se presentaron como la alternativa al fútbol y contra la desmesurada violencia que había adquirido este deporte (Torrebadella, 2013; Torrebadella y Ticó, 2014).

En el período republicano los derechos de la mujer fueron amparados por importantes cambios jurídicos como la igualdad en el derecho a voto (1931), la ley del divorcio (1932) y la legalización del aborto en Cataluña en 1936 (García, 1989; Pujadas, 2011, 2013; Simón, 2009). Asimismo las políticas educativas favorecieron el acceso del deporte a la segunda enseñanza, de manera que se priorizaron los juegos y los deportes en el programa de educación física (Cambeiro, 1997; Pastor, 1997).

En el nuevo contexto, la liberación de los derechos de la mujer tomó protagonismo desde las plataformas ideológicas de la izquierda (socialista, comunista y anarquista) en donde la mujer es vista como un camarada en igualdad de condiciones al hombre. Este ambiente se trasladó a las prácticas deportivas y al pujante ascenso de la democratización popular del deporte que se desprendía de las jóvenes estudiantes universitarias y también de la clase trabajadora, muy representada por las dependientas de comercio. En la II República el deporte femenino alcanzó una elevada participación, que solamente pudo ser frenada por la guerra civil (García, 2007; Pujadas, 2011; Carbajosa y Riaño, 2009). Esta democratización se ejemplarizó en entidades populares de signo feminista como el Club Femení i d’Esports de Barcelona, la Sección Femenina del Centre d'Esports en Lleida y, en Madrid, la Sección femenina de Hockey del Athletic Club, las Legionarias de la Salud, la Sección femenina de la FUE, el Club Femenino de Deportes o la Sociedad Femenina de Atletismo. Sin embargo, como trata Bahamonde (2011), en el proselitismo del deporte obrero, opuesto al deporte elitista y mercantilizado, existía la intención de la movilización política y social. Los deportes colectivos como el hockey hierba, el baloncesto o el hand-ball, irrumpieron con sólidos campeonatos. Asimismo, deportes como la natación o el atletismo se identificaban con la avanzada popular del deporte femenino, enfrentándose a los deportes de signo 
burgués como el tenis, el esquí o el golf. En esta situación, como también atiende Pujadas (2011), subscribimos que en España el incremento deportivo femenino no precipitó un movimiento feminista revolucionario, puesto que estuvo marcado por la impregnación liberal burguesa y no participó del activismo y la militancia internacional, como así sucedía en otros países.

En Valencia, en el campo de Mestalla, se mencionaba que las alegres artistas cultivan el fútbol refiriéndose a los equipos que confraternizaban las vedettes del Teatro Ruzaba y Apolo, en un partido benéfico para los niños del Asilo Hospital (Vidal, 1931). La noticia corrió por toda la prensa Española. Sin embargo, como trataba Malboysson (1932), hasta la fecha solamente se habían presentado algunos equipos de fútbol por la excentricidad de artistas de teatros en Valencia y Madrid que participaban en celebraciones benéficas (Fernández, 1988).

El fútbol femenino de estos años poco tenía que ver con las aspiraciones propias de las reivindicaciones feministas, antes todo lo contrario. La presencia del fútbol femenino fue una consecuencia más del mercantilismo del deporte para el placer y diversión del hombre. No podemos reconocer otro objetivo, puesto que estos equipos fueron entidades creadas artificialmente para producir un espectáculo.

Por el contrario, esta situación trató de cambiarse en Valencia con la composición de dos equipos rivales cuyo propósito era el de fomentar este deporte entre las jóvenes de Valencia, Madrid y Norte de España. En esta ciudad, en 1932, se consolidaron varios equipos femeninos de fútbol. Levante, España, Atlético y Valencia fueron considerados como los primeros equipos femeninos del fútbol profesional (Malboysson, 1932). Estas entusiastas jugadoras realizaron giras deportivas enfrentándose a un importante contingente de equipos españoles. Entre estos encuentros se destacan los realizados en las ciudades de Barcelona, San Sebastián, Oviedo, Zaragoza, Huesca, Tarragona, Alicante, Murcia, Santander, etc. Asimismo se prodigaron sus intereses en una sugestiva gira en el continente americano, disputándose encuentros en Brasil, Chile, Perú, Argentina y Méjico (García-García, 2015; Hernández, 1932).

En 1934, Ana María Martínez Sagi se convirtió en la primera mujer directiva del fútbol español al formar parte de la Junta Directiva del Fútbol Club Barcelona (García, 2007); una mujer que, como tantas otras, creía que en el deporte se encontraba el principio de la emancipación femenina (Martínez, 1930).

Con la pérdida de la España republicana, el cambio de rumbo acentuó todavía más la llamada "impenetrabilidad femenina al fútbol” (Llopis, 2011: 106).

\section{CONCLUSIONES}

Podemos generalizar que en Europa el fútbol se erigió como un inequívoco espacio (re)productor del modelo hegemónico de la masculinidad. En el caso de España, especialmente el fútbol era tenido como la matriz simbólica de la disputa por el poder de la masculinidad, espació del cual la mujer quedó apartada. La mujer tenía 
reservado en el fútbol, como en otros juegos de poder, el papel de adorno, de condescendencia, de espectadora, de trofeo incluso ante la victoria viril. Los feudos deportivos de la mujer dispusieron de la ritualidad de otras prácticas más acordes a los comedidos dispositivos de feminidad de la época: salud, fuerza y belleza.

El fútbol femenino en España se presentó originariamente como una actividad frívola y cómica de la época. Generalmente en los proyectos femeninos en torno al fútbol existía un interés puramente empresarial y especulativo, tanto como espectáculo, como para redundar en las noticias de una prensa sensacionalista. Se trató así, presentar a la mujer como un ser torpe, ridículo y cómico ante la práctica del fútbol, cuyo espectáculo solamente podía ser anecdótico o circunstancial. Con ello todavía se alejaban más las pretensiones para que algunas mujeres pudieran intentar la posibilidad del juego viril. En todo caso, como trata Mandell (1986), existió un deporte femenino ligado a los intereses de la comercialización. Las bicicletas ya cometieron este propósito a finales del siglo XIX y principios del siglo XX, pero las mujeres salvo raras excepciones tomaron parte en las competiciones deportivas.

La mujer realizó un deporte recreativo y para los dominios comerciales del hombre solamente tenía un interés productivo ligado a los nuevos cambios en los estilos de vida, pero siempre con el provecho de buscar beneficios económicos y, sobre todo, cuando se trataba del deporte socialmente diferenciado y de élite. A nadie se le ocurriría presenciar rutinariamente partidos de fútbol femeninos, cuando el fútbol masculino llenaba los estadios a millares de espectadores. El fútbol se había constituido como la salvaguarda de la nación, un poder que a partir de los años veinte trató de ser custodiado por los intereses de Estado. De cualquier modo, la II República retomó un período de libertades en donde el deporte femenino pudo ensancharse con nuevos retos. Las jóvenes estudiantes, comerciantes, trabajadoras de la clase obrera, sin cuestionar el sagrado territorio masculino del fútbol, se entregaron a otros deportes que socialmente no violentaban tanto: el hockey, baloncesto, el balonmano, la natación o el atletismo también formaron parte de la historia del deporte español. Para las mujeres el deporte representó una oportunidad de salir del hogar al estadio, y de franquear los muros de una sociedad burguesa y conservadora, que aún miraba con nostalgia el pasado y temía a las amenazas democratizadoras del futuro.

El ocaso deportivo llegó tras la Guerra Civil en donde el deporte sirvió a los intereses del Estado. En este escenario, el receso del deporte femenino truncó las aspiraciones de muchas jóvenes, puesto que su práctica se amoldó ideológicamente a las doctrinas conservadoras católicas y al condescendiente modelo de mujer rusoniana (Manrique, 2011; Pujadas, Garay, Gimeno, Llopis, Ramírez, Parrilla, 2012).

El fútbol conserva todavía hoy una elevada carga simbólica y sufraga el habitus institucional de los mayores dispositivos que ejercen el condicionamiento social de la masculinización y la feminización.

\section{REFERENCIAS BIBLIOGRÁFICAS}

A l’hora del te (1919, 16 de abril): D’Ací d'Allà, 366. 
ARNAUD, PIERRE y TERRET, THIERRY (1996): Histoire du sport féminin. Paris: L'Harmattan.

ARRECHEA, FERNANDO y SCHEINHERR, EUGEN (2015): El "Spanish girl's club” de Barcelona. Las pioneras del fútbol femenino. Cuadernos del Fútbol, 66. Tomado el 8 de julio de 1915 de:

http://www.cihefe.es/cuadernosdefutbol/2015/06/el-spanish-girls-club-de-barcelonalas-pioneras-del-futbol-femenino-espanol/

Atletismo (1922, 26 de abril): La Voz, 7.

BAHAMONDE, ÁNGEL (2011): La escalada del deporte en España en los orígenes de la sociedad de masas, 1900-1936. En X. Pujadas (coord.), Atletas y ciudadanos. Historia social del deporte en España, 1870-2010 (pp. 89-123): Madrid: Alianza Editorial.

BARBERO, JOSÉ IGNACIO (comp.) (1993): Materiales de sociología del deporte. Madrid: La Piqueta.

BASTOS, MANUEL (1927): Dos charlas sobre deportes. Madrid: Imp. Zoila Ascasibar y Compañía.

BOURDIEU, PIERRE (2000): La dominación masculina. Barcelona: Anagrama.

BRENNAM, PATRICK (2007): The munitionettes. A History of women's football in North East England during the Gran War. Rowlands Gill: Donmouth Publishing.

BRULE, JEANNE (1920, 15 de febrero): Los deportes y la mujer. Heraldo Deportivo, 59-60.

BURGOS, INÉS (2001): Gregorio Marañón. Sexo, trabajo y deporte. Ágora para la EF y el Deporte, 1, 97-102.

CAGIGAL, JOSÉ MARÍA (1981): ¡Oh deporte; (Anatomía de un gigante): Valladolid: Miñón.

CAMBEIRO, JUAN ANDRÉS (1997): El proceso de institucionalización de la educación física en la España contemporánea. Barcelona: Departamento de Historia y Teoría de la Educación, Universidad de Barcelona. [tesis doctoral no publicada]

CARBAJOSA, CONCEPCION y RIAÑO, CATALINA (2009): Proceso histórico de la incorporación de la mujer española a la práctica deportiva en el primer tercio del siglo XX. Conceptualización a través de la prensa escrita de la época, Citius, Altius, Fortius: humanismo, sociedad y deporte: investigaciones y ensayos, 2(1), 23-47.

CARBAJOSA, CONCEPCIÓN y RIAÑO, CATALINA (2010): Memorias olímpicas. Lilí Álvarez: trayectoria e identidad deportiva. Citius, altius, fortius: humanismo, sociedad y deporte: investigaciones y ensayos, 3(1), 57-79.

Ciclismo femenino (1925, 5 de octubre): Heraldo Deportivo, 416. 
DE CASTRO LES, VICENTE (1906, 1 de diciembre): La intervención de las mujeres en el sport. Gran Vida, 1-5.

DE CAVIA, MARIANO (1920, 25 de mayo): Balompie femenino. Heraldo Deportivo, 201-204.

DE LA ARADA, RAQUEL; TURRÓ GUILLEM y VILANOU, CONRAD (2013): Lilí Álvarez: del tenis a la plenitud vital. La teoría de la formación de una mujer comprometida. Innovación Educativa, 23, 47-59.

DE LAIGLESIA, MARCIAL (1926, 9 de enero): Los “onces” femeninos. Muchas gracias, 16.

DEL CAMPO, ALBERTO (2003): Cuestión de pelotas. Hacerse hombre, Hacerse el hombre en el Fútbol. En J. M. Valcuende y J. Blanco (ed.), Hombres. La construcción cultural de las masculinidades (pp. 66-99): Madrid: Talasa.

DEL CAMPO, LUIS (1931, 15 de diciembre): Legionarias de la Salud. Mundo Gráfico, 27-28.

DEL OLMET, LUIS ANTON (1922, 25 de mayo): El deporte femenino. Heraldo de Madrid, 3.

Deportes femeninos (1918, 5 de mayo): Heraldo Deportivo, 10.

Deportes y el feminismo (1925, 1 de agosto): Gran Vida, 260-261.

DUNNING, ERIC (2003): El fenómeno deportivo. Estudios sociológicos en torno al deporte, la violencia y la civilización. Barcelona: Paidotribo.

El deporte ridiculizado (1923, 15 de agosto): La Jornada Deportiva, 7.

El foot-ball femenino en España (1920, 13 de diciembre): Heraldo de Madrid, 5.

El hockey y el feminismo (1923, 1 de enero): Gran Vida, 13.

ELÍAS, JOSEP (1918): Per què fem esport II. Quadenrs d'Estudi, 2(2), 122-131.

Femeninas (1923, 5 de desembre): Heraldo Deportivo, 511.

Femenine football. A revolting exhibition (1895, 10 de mayo): The Mercury, 3.

Feminismo deportivo (1921, 5 de octubre): Heraldo Deportivo, 368-369.

Feminismo deportivo (1922, 25 de abril): Heraldo Deportivo, 362-363.

FERNÁNDEZ, MARÍA ROSA (1988): Mujer y deporte en Madrid durante el primer tercio del siglo XX. En R. Zabalza (coord.), Orígenes del deporte madrileño, 18701936. Condiciones sociales de la actividad deportiva (pp.117-167): Madrid: Ed. Comunidad de Madrid.

Festival de artistas de varietés (1914, 18 de marzo): Mundo Gráfico, 19.

FRANCO (1895a, 12 de marzo): Crónica de Sport. La Vanguardia, 3.

FRANCO (1895b, 4 de abril): Crónica de Sport. La Vanguardia, 3. 
Fútbol femenino (1925, 21 de octubre): La Libertad, 4.

G-LUQUE, XAVIER (2011, 27 de febrero): Al fútbol con faldas y cuando Barcelona descubrió el interés femenino por el fútbol. Las Spanish Girls. La Vanguardia, 70.

GARCÍA-CASTELL, JOAN (1968): Historia del futbol català. Barcelona: Aymà.

GARCÍA-FERRANDO, MANUEL (1989): La participació femenina de l'esport, en relació a la masculina. En R. Rello (coord.), Dona i esport (pp. 50-63): Barcelona: Ajuntament de Barcelona.

GARCÍA-GARCÍA, JORGE (2015): Origen del deporte femenino en España. Madrid: Jorge García García.

GARCÍA, JULIÁN (2007): El deporte en la Guerra Civil. Madrid: Espasa.

GARCÍA, MILAGROS (1989): L’inici de l'esport femení. En R. Rello (coord.), Dona i esport (pp. 23-37): Barcelona: Ajuntament de Barcelona.

GARCÍA, MILAGROS (1992): Las mujeres y el deporte: del corsé al chándal. Sistema, 110-111, 37-57.

GONZÁLEZ, TERESA (2011): Sport, Nationalism and Militarism. Alfonso XIII: Sportsman, Soldier, King. The Intarnational Journal of the History of Sport, 28(14), 1987-2030. doi: 10.1080/09523367.2011.604825

GUARDIOLA, ENRIQUE (1923, 15 de septiembre): Girls contra madeimoselles. Fiesta deportiva a favor de los periodistas. Stadium, 594-595.

HARGREAVES, JENNIFER (1993): Promesa y problemas en el ocio y los deportes femeninos. En J. I. Barbero (comp.), Materiales de sociología del deporte (pp. 109132): Madrid: La Piqueta.

HERNÁNDEZ (1932, 26 de julio): Presentamos a ustedes a las primeras futbolistas profesionales que ha dado España. As, 6-7.

ISOP (1923, 3 de junio): El futbol jugat per dones. La Publicitat, 2.

IZQUIERDO, EUGENIO y GÓMEZ, MARÍA TERESA (1999): La difícil incorporación de la mujer española a la locura velocipédica del siglo XIX. En Actes del quart congrés de les ciències de l'esport, L'educació i la recreació de l'INEFC de Lleida (pp. 117-125): Lleida: INEFC-Lleida.

J. E. (1928, 1 de abril): Futbolismo y boxeo. Acción Cultural, 1.

JUSTRIBÓ, DANIEL (2014): Feminitat, esport, cultura: pioneres de l'atletisme català (1921-1938): Barcelona: Daniel Justribó.

La educación física de la mujer (1922, 15 de agosto): La Jornada Deportiva, 2.

Las niñas futbolistas (1914a, 11 de junio): El Mundo Deportivo, 4.

Las niñas futbolistas (1914b, 18 de junio): El Mundo Deportivo, 5. 
LLOPIS, RAMÓN (2010): Masculinidades inductoras. La construcción de la masculinidad en el fútbol español. Sistema, 217, 61-76.

LLOPIS, RAMÓN (2011): Identitats de gènere i esport. Masculinitats inductores i resistències a la masculinitat hegemónica al futbol español. Anuari de Psicologia, 13(1-2) 93-108.

LÓPEZ-VILLAR, CRISTINA (2014): The Beginnings of Hockey in 1930s Galicia (Spain): A Female Phenomenon. The International Journal of the History of Sport, 31(9), 1133-1157.

Los deportes apropiados para la mujer (1922, 1 de octubre): Gran Vida, 309.

MALBOYSSON, ENRIQUE (1932, 2 de julio): Las señoritas futbolistas. Stampa, 3324.

MALUQUER, ALBERTO (1923, 7 de marzo): Fútbol femenino. La Jornada Deportiva, 2.

MANDELL, RICHARD (1986): Historia cultural del deporte. Barcelona: Bellaterra.

MANRIQUE, JUAN CARLOS (2011): Juventud, deporte y falangismo. El frente de Juventudes, la Sección Femenina y los deportes del “movimiento”. En X. Pujadas (coord.), Atletas y ciudadanos. Historia social del deporte en España, 1870-2010 (pp. 233-272): Madrid: Alianza Editorial.

MARAÑÓN, GREGORIO (1934): Tres ensayos sobre la vida sexual. Sexo trabajo y deporte. Maternidad y feminismo. Educación Sexual y diferenciación sexual $\left(7^{\mathrm{a}}\right.$ ed.). Madrid: Biblioteca Nueva.

MARIA (1923, 3 de junio): La dona i l'esport. La Publicitat, 1.

MARTÍN, ANTONIO y GARCÍA, ALMUDENA (2011): Construyendo la masculinidad: fútbol, violencia e identidad. Revista de Investigaciones Políticas y Sociológicas, 10(2), 73-95.

MARTÍNEZ, ANA MARÍA (1930, 10 de febrero): Unas palabras de María Teresa Vernet. El deporte puede ser el principio de la emancipación femenina. Deportes, 2.

MARTORELL, PELAYO (1923, 25 de agosto): Opiniones. La sporwomen. El País, 1.

MASON, TONY (1994): El deporte en Gran Bretaña. Madrid: Civitas.

MÉNDEZ, L. (1930, 5 de julio): Mañana jugaran en Chamartín un equipo femenino de Romea contra otro del Metropolitano. Heraldo de Madrid, 8.

MESTOAR (1922, 24 de agosto): La mujer y el deporte. Madrid-Sport, 3-4.

MOLLÁ (1931): La mujer y el deporte. Madrid: Lib. Médica de R. Chema y Compa .

NAVARRO, EMILIO (1917): Álbum histórico de las sociedades deportivas de Barcelona. Barcelona: Imp. José Ortega.

Noticias de sociedad (1923, 3 de noviembre ): La Época, 2. 
PARDO, EMILIA (1896, 6 de julio): Vida contemporánea. Polo. La Figura Artística, 466.

PASTOR, EL (1897, 25 de marzo): Ciclismo. Nuevo Mundo, 10.

PASTOR, JOSÉ LUIS (1997): El espacio profesional de la educación Física en España: génesis y formación (1883-1961): Alcalá de Henares: Universidad de Alcalá de Henares.

PASTOR, JOSÉ LUIS (2011): La aparición de la actividad físico deportiva del 'bello sexo' en España. Un referente histórico revelador. En P. Scharagrodsky (coord.), La invención del 'homo gymnasticus'. Fragmentos históricos sobre la educación de los cuerpos en movimiento en Occidente (pp. 189-211): Buenos Aires: Prometeo.

Por el montepío de actores (1930, 22 de mayo): Heraldo de Madrid, 5.

PORRAS, EMILIO CÉSAR (1925): Educación física. Concepto general, desde el punto de vista higiénico, de los deportes actuales y su acción benéfica o perjudicial en el desarrollo de la juventud. Madrid: Imp. de la Ciudad Lineal.

PUJADAS, XAVIER (2011): Del Barrio al estadio. Deporte, mujeres y clases populares en la segunda República, 1931-1936 (pp. 125-167): En X. Pujadas (coord.), Atletas y ciudadanos. Historia social del deporte en España, 1870-2010. Madrid: Alianza Editorial.

PUJADAS, XAVIER (2013): De espectadoras a protagonistas. Las mujeres y el deporte en la II $^{\text {a }}$ República española (1931-1936): En III Ciclo de conferencias: xénero, actividade física e deporte (2011-2012) (pp. 47-57): A Coruña: Universidade da Coruña. Tomado el 13 de octubre de 2013 de http://hdl.handle.net/2183/11570.

PUJADAS, XAVIER; GARAY, BEATRIZ; GIMENO, FERNANDO; LLOPIS, RAMÓN; RAMÍREZ, GONZALO y PARRILLA, JOSÉ MANUEL (2012): Mujeres y deporte durante el franquismo (1939-1975): Estudio piloto sobre la memoria oral de las deportistas. Materiales para la Historia del deporte, 10, 37-53.

R. R. F. (1926, 25 de octubre): Atletismo femenino. Heraldo Deportivo, 447-449.

Real Sociedad Gimnástica Española (1921, 15 de septiembre): El sport femenino en Madrid. Madrid-Sport, 12.

REAL, NEUS (1998): El Club Femení i d'Esports de Barcelona, plataforma d'acció cultural. Barcelona: Publicacions de l'Abadia de Montserrat.

REAL, NEUS (2010): Dona i esport a la Catalunya dels anys trenta. Barcelona: Generalitat de Catalunya, Consell Català de l'Esport.

RIAÑO, CATALINA (2004a): Primera parte: Vida y obra de Elia María González Álvarez y López Chicheri, "Lilí Álvarez”. Parte I. Colección ICD: Investigación en Ciencias del Deportes, 38, 25-55. 
RIAÑO, CATALINA (2004b): Segunda parte: Dimensión de lo deportivo en la obra de Lilí Álvarez. Parte I. Colección ICD: Investigación en Ciencias del Deportes, 38, 91-132.

RODRÍGUEZ, DOMINGO; MARTÍNEZ, MARÍA JOSÉ y MATEOS, COVADONGA (2005): Identidad y estereotipos de la mujer en el deporte. Una aproximación a la evolución histórica. Revista de Investigación en Educación, 2, 199-126.

RUBRYK [Sánchez Arias, Román] (1921): Cartas a Fernanda. La educación de mujer para madre. Madrid: Imp. de Juan Pueyo.

SÁNCHEZ, FERNANDO (2005): Fuentes documentales deportivas aplicadas a la historia de un club deportivo español: Historia del Club Atlético de Madrid. Universidad Complutense de Madrid: Departamento de Biblioteconomía y Documentación.

SÁNCHEZ, RAÚL y RIVERO, ANTONIO (2013): 'Governmentality' in the origins of European female PE and sport: the Spanish case study (1883-1936): Sport, Education and Society, 18(4), 494-510. Doi: 10.1080/13573322.2011.601735

Señoras pelotaris (1895, 18 de abril): El Pelotari, 643.

SIMÓN, JUAN ANTONIO (2009): El papel de la mujer en el origen y desarrollo del deporte en España, 1900-1939. En L. Branciforte, C. González, M. Huguet, y R. Orsi (eds.), Actas del primer Congreso Internacional. Las mujeres en la esfera pública. Filosofía e historia contemporánea (pp. 77-102): Madrid: Compañía Española de Reprografía y Servicios S. A.

SOLER, SUSANA (2009): Los procesos de reproducción, resistencia y cambio de las relaciones tradicionales de género en la Educación Física: el caso del fútbol. Cultura y Educación, 21(1), 31-42. Doi: 10.1174/113564009787531253

TATE, TIM (2013): Girls with Balls - The Secret History of Women's Football. London: John Blake Publishing.

TORREBADELLA FLIX, XAVIER (2014): Regeneracionismo e impacto de la crisis de 1898 en la educación física y el deporte español. Arbor, 190(769): a173. doi: http://dx.doi.org/10.3989/arbor.2014.769n5012

TORREBADELLA-FLIX, XAVIER y TICÓ, JORDI (2014): Notas para la historia del centenario del baloncesto español. Un deporte escolar y popular para ambos sexos (1897-1938): E-Balonmano.com: Revista de Ciencias del Deporte, 10(3), 177-198.

TORREBADELLA, XAVIER (2011a): La educación física y la actividad gimnásticodeportiva de las mujeres a partir de la bibliografía especializada del siglo XIX. Arenal, 18(1), 147-179.

TORREBADELLA, XAVIER (2011b): Repertorio bibliográfico inédito de la educación física y el deporte en España (1800-1939): Madrid: Fundación Universitaria Española. 
TORREBADELLA, XAVIER (2012): El deporte contra la educación física. Un siglo de discusión pedagógica y doctrinal en la educación contemporánea. Movimiento humano, 4, 73-98.

TORREBADELLA, XAVIER (2013): Anotaciones al balonmano en el contexto histórico del deporte en España (1900-1939): E-balonmano.com: Revista de Ciencias del Deporte, 9(2), 115-134.

TRABAL, JOSEP ANTONI (1926, 6 de septiembre): L'esport femení. L’Esport Català, 1.

UEFA (2015): Women's football across the national associations 2014-2015. UEFA. http://www.uefa.org/MultimediaFiles/Download/OfficialDocument/uefaorg/Wome n'sfootball/02/30/93/30/2309330_DOWNLOAD.pdf

Última hora deportiva (1931, 9 de diciembre): Crónica, 26.

URÍA, JORGE (2008): Imágenes de la masculinidad. El futbol español en los años veinte. Ayer, 72, 121-155.

VIDAL, ANTONIO (1923, 17 de abril): El deporte femenino. La Copa San Dionis de hockey. Heraldo de Madrid, 4.

VIDAL, VICENTE (1931, 7 de enero): El deporte en broma, Un partido de fútbol femenino en Valencia. Mundo Gráfico, 50-51. 